* Mestre em Direito Estado e Cidadania pela Univer-sidade Gama Filho, UGF, Brasil. E-mail: joao.esteves1000@gmail.com ** Pós-Doutor pela Universidad de Granada, UGR, Espanha; Doutorado em Direito pela Universidade Federal de Santa Catarina, UFSC, Brasil. E-mail: joao.esteves1000@gmail.com

\section{A ideologia da neutralidade: uma abordagem sobre o juspositivismo normativista e seus limites frente à democracia social}

\section{THE IDEOLOGY OF NEUTRALITY: AN APPROACH OF ABOUT TO NORMATIVE POSITIVISM AND ITS LIMITS IN FRONT OF SOCIAL DEMOCRACY}

\author{
João Luiz Martins Esteves * \\ Luiz Henrique Urquhart Cademartori **
}

Resumo: O presente trabalho aborda seu objeto a partir da existência da crítica que se faz ao positivismo jurídico normativista quanto à sua falta de compromissos relativos aos valores decorrentes das atuais democracias social-liberais, e também da própria postura de indiferença apresentada pela Teoria Pura do Direito quanto ao conteúdo ideológico dos sistemas jurídico-legais. Isto tudo se realiza a partir de uma postura de pretensa neutralidade do Positivismo Jurídico. Considerado isto, o presente trabalho investiga qual é o compromisso ideológico do juspositivismo normativista e sua possibilidade de dar uma resposta adequada às críticas que lhe são feitas.

Palavras-chave: Direito. Ideologia. Neutralidade. Positivismo.

Abstract: The present paper approaches its subject from the existence of the criticism that is made to normative legal positivism regarding its lack of commitments related to the values derived from the current social-liberal democracies, as well as the own posture of indifference displayed by the Pure Theory of Law regarding the ideological content of the law and legal systems. All this is carried on from a position of supposed neutrality of Legal Positivism. Deemed this, the present paper investigates what is the ideological commitment of the normative juspositivism and its possibility to give an adequate answer to the criticisms submitted to them.

Keywords: Law, Ideology, Neutrality, Positivism. 


\section{INTRODUÇÃO}

A Teoria Pura do Direito pode ser considerada uma das principais obras jurídicas do século XX. A afirmação quanto a esse protagonismo justifica-se em virtude de que o método desenvolvido por Hans Kelsen (1996) é percebido como sendo um paradigma e referencial teórico presente não somente em manuais de direito, como também nas principais construções teóricas realizadas no direito ocidental desde a sua edição até os dias atuais. Entretanto, podem ser encontradas, além de defesas ou complementos à teoria jusposivista normativista, contundentes críticas a este modelo teórico, as quais contestam a sua adequação como método de interpretação e aplicação do direito nos Estados democráticos e sociais contemporâneos cujas sociedades, e consequentemente a respectiva comunidade jurídica destes, exigem não somente uma aproximação efetiva entre direito e justiça, mas também a manutenção das conquistas históricas no campo da democracia e dos direitos humanos inclusive por meio da atuação jurisidicional. É possível afirmar que não tem sido uma tarefa fácil a estas concepções teóricas jurídicas impor uma total derrota ao positivismo jurídico normativista. A prova da existência desta colisão de teorias pode ser observada no persistente debate entre as concepções não positivistas ou de um positivismo crítico e o positivismo jurídico normativista, o qual tem se arrastado sem que haja uma posição triunfante ao final.

Sem a necessidade de confrontação detalhada entre o positivismo normativista e as concepções que se contrapõem a ela, é possível destacar que as teses substancialistas ou procedimentalistas desenvolvidas ente outros por Dworkin (2005), Alexy (2011) e Habermas (2012), movem-se conjuntamente no entendimento de que a fonte do direito não é exclusivamente legislativonormativa, e também que uma das pesadas críticas ao positivismo jurídico pode ser traduzida pela observação de que a utilização de seu método descritivo do direito, o qual é indiferente ao conteúdo e caráter político da fonte normativa, pode servir à legitimação de Estados e de governos não democráticos e descomprometidos com um consenso de justiça possível de ser definido por valores universais ou comunitários. Esta última crítica pode ser encontrada tanto no denominado "movimento crítico"1 de vertente marxista, que no Brasil

\footnotetext{
${ }^{1}$ Conforme Luiz Fernando Coelho, [...] "nem Kelsen foi neutro. Pelo contrário, sua Teoria Pura é o mais seguro indicador de uma ideologia. Tal ideologia no aspecto externo atende ao interesse de justificar o afastamento dos juristas da problemática social. Assim serviu aos donos do poder: quanto menos se questionasse o aspecto ético do exercício do poder, melhor" (COELHO, 1985, p.47).
} 
foi influenciado por Michael Miaille (2005), quanto em teses jus-positivistas de teor crítico, de que é exemplo a teorização de Lugi Ferraioli (1998), a qual contrapõe-se ao modelo kelseniano sob o entendimento de que uma norma vigente e eficaz não é, somente por isto, válida. Estas correntes, conjugam-se na necessidade de correção diante do desencontro existente entre o conteúdo da norma positivada e o real sentido de justiça que pode ser buscado fora ou além do direito posto.

Por sua vez, os adeptos do juspositivismo normativista, em que pese não desconhecerem o caráter político do direito, reafirmam argumentos em que defendem que toda norma vigente e eficaz é válida juridicamente, independente do seu conteúdo (DIMOULIS, 2006, p. 116) e de que há necessidade de haver uma neutralidade política e ideológica no momento em que se estuda e se aplica o direito, conforme se observa nas palavras de Dimitri Dimoulis ao defender o que denomina positivismo jurídico stricto senso:

[...] o aplicador e estudioso devem entender e implementar a vontade dos criadores das normas, distanciando-se de suas convicções morais e políticas. Essa opção não se justifica em nome de uma ingênua crença na neutralidade política do direito ou em virtude da, igualmente ingênua, crença na apoliticidade dos aplicadores e estudiosos. O objetivo é manter o rigor das decisões e afirmações sobre os conteúdos do direito. Somente quem adota uma postura de neutralidade política pode revelar e preservar a normatividade jurídica, respeitando a vontade política do legislador. (DIMOULIS, 2006, p.108).

A ideia de neutralidade do estudioso e do aplicador do direito, acima exposta, não surge por acaso, é dependente de um anterior e primeiro conceito de neutralidade presente no método juspositivista desenvolvido por Kelsen que se traduz em uma premissa de base epistemológica central na teoria kelseniana: o conceito de neutralidade ideológica como condição de conhecimento sobre o direito.

Neste trabalho, sob uma análise crítica do modelo kelseniano, com a intenção de investigar qual a possibilidade de que o positivismo normativista dê uma resposta adequada às críticas que lhe são feitas e também, buscando demonstrar qual o fundamento radical que opõe o positivismo de tipo kelseniano a todas as demais concepções jurídicas da atualidade, privilegiase um dos de seus aspectos, o qual diz respeito à sua pretensão de neutralidade ideológica. 
Não trata-se, portanto, de analisar a ideologia de Kelsen, mas sim o viés ideológico embutido no método de compreensão do direito por ele desenvolvido a partir de sua obra Teoria Pura do Direito.

\section{A PRETENSÃO DE CARÁTER ANTI-IDEOLÓGICO DO POSITIVISMO KELSENIANO}

No desenvolvimento de sua teoria, Kelsen teve como proposta o conhecimento do que é o direito para todo e qualquer direito positivo em qualquer época e lugar. Para o professor austríaco isto seria possível se fosse dado ao direito um caráter científico. Mas não bastava somente isso, realizando um trabalho de característica epistemológica entendeu que, para uma possível realização desta tarefa proposta, precisaria ainda estabelecer o que é ciência e o que não é ciência no direito.

Ao elaborar sua teoria Kelsen deixou claro que esta tinha como alicerce estabelecer uma "verdadeira ciência do direito" (KELSEN, 1996, p. 118) que, em contraposição ao que alegou ser uma antecedente e tradicional ciência jurídica, estivesse despida de qualquer viés ideológico. A falsa ciência jurídica que atacou, dizendo que encontrava-se comprometida ideologicamente, dizia o direito como deveria ser, ao contrário da verdadeira ciência do direito, a qual teria como tarefa dizer o direito tal como ele é. Sob este entendimento, a Teoria Pura recusar-se-ia "a servir quaisquer interesses políticos, fornecendo-lhes as "ideologias" por intermédio das quais a ordem social vigente é legitimada ou desqualificada" (KELSEN, 1996, p. 118).

Vê-se claramente que Kelsen entendia e indicava que a teoria que formulara não correspondia e não servia a qualquer ideologia. E apontou como orientação metodológica desta teoria, livrar de qualquer conteúdo aquilo que entendia ser o direito, reduzindo o conceito deste a 'sistema normativo'. Para o professor vienense, a comprometida ideologia jusnaturalista, estaria encobrindo a realidade do direito. A partir deste esforço o direito estaria purificado, livre de qualquer intromissão externa, e a verdade sobre o direito estaria demonstrada cientificamente, pelo motivo de que estaria livre da ideologia. Isto tudo fica explicitado se observarmos as próprias palavras de Kelsen quando expõe o que entende na relação entre ciência e ideologia: 
Precisamente através desta sua tendência anti-ideológica se revela a Teoria Pura do Direito como verdadeira ciência do Direito. Com efeito, a ciência tem, como conhecimento, a intenção imanente de desvendar o seu objeto. A "ideologia", porém, encobre a realidade enquanto, com a intenção de a conservar, de a defender, obscurece ou, com a intenção de atacar, de a destruir e de a substituir por uma outra, a desfigura. (KELSEN, 1996, p.119).

Estas palavras de Kelsen demonstram um reduzido entendimento quanto ao que é ideologia, finca-se em um significado para ideologia que é o de "falsa consciência" que implica ilusão ou deformação da realidade ${ }^{2}$ que não leva em consideração outros possíveis significados do termo, como "tomada de posição", "instrumento de análise crítica", "instrumento de justificação" - como programa de ação - (FERRAZ JR., 1998, p. 182-183), como discurso (EAGLETON, 1997, p. 171-192) ou ainda como linguagem ${ }^{3}$. Ao mesmo tempo Kelsen demonstra apegar-se à concepção positivista desenvolvida por Auguste Comte ${ }^{4}$ a qual "afirma a necessidade e a possibilidade de uma ciência social completamente desligada de qualquer vínculo com as classes sociais, com posições políticas, os valores morais, as ideologias, as utopias, as visões de mundo" (LÖWY, 2010, p. 39).

Esta postura positivista ou neopositivista, adotada por Kelsen, envolvese em problemas de três ordens ligadas às relações existente entre: a) ciência e ideologia; b) direito e ciência; b) direito e ideologia. A seguir serão trabalhadas as três relações com o fim de identificar a proposta kelseniana, e ao final compreender se é possível ao positivismo jurídico responder adequadamente às críticas que lhe são feitas quanto à sua impossibilidade de compatibilizar-se com os valores democráticos e com a aproximação entre direito e justiça realizáveis a partir da preservação de conquistas democráticas e sociais.

\footnotetext{
${ }^{2}$ Este significado de ideologia, que deriva do sentido dado ao termo por Napoleão Bonaparte ao contrapor-se a Destutt de Tracy no início do século XIX, foi utilizado por Karl Marx a partir de 1846 no livro "A Ideologia Alemã", e "continua sua trajetória no marxismo posterior a Marx, sobretudo na obra de Lenin, onde ganha um outro sentido, bastante diferente: a ideologia como qualquer concepção da realidade social ou política, vinculada aos interesses de certas classes sociais" (LÖWY, 2010, p. 1112).

${ }^{3}$ FERRAZ JR. (1998, p. 183)., admite o termo ideologia como um conceito axiológico, explicitando que a linguagem ideológica é também valorativa. Fazendo referência a Umberto Eco, exemplifica a neutralização de valores por meio desta metacomunicação (valoração ideológica) da seguinte forma: "a liberdade é um valor mas, no discurso dogmático, ela é sempre liberdade no sentido liberal, conservador, fascista, comunista etc"

${ }^{4}$ No desenvolvimento de sua teoria positivista Auguste Comte, teve como precursor Saint-Simon que considerava-se discípulo de Condorcet (LÖWY, 2010, p. 41).
} 


\subsection{Ciência e ideologia}

Não é adequado querer diferenciar a ciência da ideologia, como se aquela pudesse se libertar das ideologias presentes nas mentes dos que constroem a ciência. Esta não é algo que existe sem a intervenção humana e como tal, fatalmente está carregada de todas as insuficiências humanas. Nós humanos não demonstramos ainda a nós mesmos que é possível criar qualquer coisa, e especificamente um método racional de apreensão e compreensão do mundo que esteja totalmente desvinculado dos valores que carregamos. E é factível dizer que uma vontade epistemológica de desprendimento valorativo, desbravadora de um caminho orientado ao encontro de um saber que poderia se denominar de "conhecimento verdadeiro", seja ela mesma - em face da sua pretensão - uma ilusão carregada de ideologia.

O conhecimento realiza-se por meio de exercícios construídos racionalmente a partir da observação que o sujeito faz sobre o seu objeto. Entretanto, sujeitos diferentes podem ter percepção de realidade diferente sobre o objeto observado, e portanto teriam percepções diferentes sobre o que poderia ser entendido como verdade. Mais do que isto, um mesmo sujeito, a partir de mudança de paradigmas pode enxergar o objeto de forma diferente, conforme já observado por Thomas S. Kuhn (2005, p. 159) ao analisar as modificações da percepção humana sobre a realidade a que está submetido o cientista a partir da mudança paradigmática na ciência. Esta constatação fatalmente levou Kuhn a anunciar uma incerteza quanto à efetiva possibilidade de se encontrar uma verdade científica, pelo menos em termos absolutos, quando afirma que

[...] talvez tenhamos que abandonar a noção, explícita ou implícita, segundo a qual as mudanças de paradigma levam os cientistas e os que com eles aprendem a uma proximidade maior da verdade. (KUHN, 2005, p. 215)

Não há como duvidar que o observador sempre carrega consigo, de forma imanente, uma ideologia qualquer, sob qualquer um de seus significados, resultado das suas próprias experiências, da qual não se pode libertar quando

\footnotetext{
${ }^{5}$ Em que pese ser possível identificar na obra de Thomas S. Khun, que sua preocupação está menos voltada às Ciências Sociais do que aqueles que podem ser denominadas como Ciências 'duras', como a física e a química, a apresentação de seu pensamento na forma exposta neste trabalho não torna-se despropositada. Pelo contrário, se o autor retira estas conclusões das observações realizadas na física ou na química, cuja objetividade está mais presente do que nas Ciências Sociais, então mais ainda se mostram adequadas também em relação a estas últimas onde é maior o grau de subjetividade.
} 
observa o seu objeto. A imanência desta ideologia na atividade cognitiva do observador, fatalmente interfere no resultado da observação realizada. O fator ideológico estará presente no método, que dele não ficará livre, como também estará presente na atividade congnitiva desenvolvida pelo observador que aplica o método, e não deve ser visto apenas como elemento perturbador do conhecimento científico, mas também como elemento que o ilumina e faz avançar.

Quando, na apresentação de um método e também na sua utilização não são explicitadas as condições ideológicas, sociológicas, econômicas e culturais do método utilizado, condições estas que devem explicitar as possíveis tarefas políticas às quais se pode prestar o método, mais distante fica uma pretensa verdade, ou pelo menos de uma demonstração possível da realidade.

Os objetos da ciência não podem ser compreendidos sem o valor que damos a eles, sendo mesmo necessário que seja identificado e exposto durante o exercício descritivo, configurando isto uma lealdade do observador para com a ciência e também condição necessária de produção de cientificidade, conforme observado por Edgard Morin:

A vontade de encontrar uma demarcação nítida e clara da ciência pura, de fazer uma decantação, digamos, do científico e do não-científico, é uma idéia errônea e diria também uma idéia maníaca. Na minha opinião, esse foi um dos raros e grandes erros de Popper. O notável é que a ciência não só contém postulados e "themata" não-científicos, mas que estes são necessários para a constituição do próprio saber científico, isto é, que é preciso a nãocientificidade para produzir a cientificidade, do mesmo modo que, sem cessar, produzimos vida com a não-vida. (MORIN, 2000, p. 8)

Com relação ao estabelecimento de métodos científicos, e crê-se que principalmente nas denominas ciências sociais "é necessário que toda a ciência se interrogue sobre suas estruturas ideológicas e seu enraizamento sócio-cultural" (MORIN, 2000, p. 26). Somente assim, analisando não somente o objeto, mas também o método de análise que se propõe, é possível entender qual o papel ideológico que um determinado método de investigação, principalmente quando aplicado nas relações sociais, a fim de que seja possível entender o resultado da investigação. Mais ainda, quando se ideologiza o método por meio da desvaloração do objeto, sob o argumento de revelar a verdade nele contida (se é que isto é possível), faz-se justamente algo que se distancia da pretensão apresentada pois, desta forma, se reduz e se desfigura o objeto, tornando o resultado da observação somente uma visão caricaturada deste mesmo objeto. 


\subsection{Direito e ciência}

Influenciado pela ideia fundamental do método positivista de que a ciência só pode ser objetiva e verdadeira na medida em que eliminar totalmente qualquer interferência de valores Kelsen propõe uma aproximação entre direito e ciência sob a condição de pureza científica. E conforme já exposto anteriormente pode-se afirmar, a partir da construção desenvolvida na obra Teoria Pura do Direito, que ciência e verdade devem ser tidas como indissociáveis. O encontro com a 'verdade' - como realidade possível de ser observada a partir da exclusão de elementos ideológicos - é elemento fundamental da pretensão de kelseniana. E, portanto, sendo o direito, o objeto proposto por Kelsen, a verdade buscada por seu método é, portanto, a verdade em relação ao que é o direito. Para ele, a verdade sobre o que é o direito, somente poderia ser alcançada caso a ciência a ser utilizada também, no seu entender, fosse verdadeira.

Para encontrar a verdade que procura, em relação ao seu objeto, Kelsen realiza dois exercícios metodológicos. O primeiro deles consistiu-se em delimitar a amplitude do seu objeto. E o fez elegendo o sistema legislativo estatal a que denomina de direito positivo. Excluiu de sua apreciação qualquer outro sistema normativo (moral, político, etc...) que não seja o sistema imposto lesgislativamente pela autoridade estatal. Ao fazer esta delimitação do seu objeto de estudo, inicia a partir daí a formação do seu método cognitivo. A redução da complexidade daquilo que entende ser o direito é uma opção de escolha e se apresenta, portanto, como parte integrante do método proposto. Verifica-se desde aí, um problema na teoria pura do direito: uma confusão entre o objeto e o método de análise deste mesmo objeto. Esta situação, em que o objeto proposto é condição para utilização do método escolhido tem consequências sobre o que poderia ser entendido como uma ciência do direito, como se verá na sequência, e se configura como sendo o segundo exercício metodológico de Kelsen.

O método kelseniano, descarta qualquer análise sobre o conteúdo do sistema normativo escolhido como objeto. Kelsen pretende realizar um apartamento da sua teoria de tudo que possa estar relacionado a algum valor. Conforme a teoria pura do direito, aquilo que denomina ciência jurídica, o exercício de conhecimento da verdade sobre o direito é realizado por meio de uma verificação descritiva do sistema normativo (KELSEN, 1996, p. 82), ou seja, uma mera repetição do que está escrito nas normas jurídicas 
e das relações, por estas constituídas, entre fatos que as mesmas normas determinam. Cria-se um divisor entre o direito, como ordem normativa da conduta, e as diversas relações humanas.

Agostinho Marques Neto, sem desconsiderar a possibilidade de existência de uma ciência do direito, aponta a delimitação proposta por Kelsen como expressão do mito positivista, de que a natureza do objeto define o campo das ciências (MARQUES NETO, 2001, p. 165). Encontramos dentro deste embate, um desacordo quanto à definição do objeto de uma ciência do direito onde Marques Neto, entendendo que a norma é muito mais aplicação técnica da ciência do direito do que objeto dessa ciência, afirma que "não é em função do objeto que se distinguem as disciplinas científicas, mas em razão dos problemas que elas se propõem" (MARQUES NETO, 2001, p. 178), e que o objeto principal de uma ciência do direito é o fenômeno jurídico, que não se encontra em estado puro na sociedade "e que se gera e se transforma no interior do espaço-tempo social por diferenciação das relações humanas, tal qual acontece com os demais fenômenos sociais específicos: políticos, econômicos, morais, artísticos, religiosos etc" (MARQUES NETO, 2001, p.186).

Disto decorre que, a falta de identificação de um problema, aliada à escolha de um objeto insípido, como é a norma destituída de conteúdo, e também a falta de interdisciplinaridade são, com certeza, o principal obstáculo epistemológico da proposta kelseniana de conhecimento do direito.

É importante destacar que Kelsen não ignora a influência que tais fatores exercem sobre a elaboração jurídica, mas na intenção de possibilitar coerência à sua teoria tenta demonstrar a neutralidade de sua fórmula utilizando uma distinção entre seu método e as denominadas ciências naturais, por estar isento de caráter ideológico sob dois argumentos básicos: a) substituindo a causalidade pela imputação; b) substituindo a razão por um axioma: a norma hipotética fundamental.

O primeiro argumento apresentado por Kelsen estaria no fator de que as ciências naturais se informam pela lei da causalidade em que prevaleceria uma "lei natural" que associa determinado fato, como uma causa, a um outro fato, como efeito daquela causa, enquanto que seu método, o qual tem como objeto a ordem normativa da conduta dos homens entre si, tem como principio ordenador não a causalidade mas sim a imputação.

Esta categoria principiológica kelseniana - a imputação - apresenta-se como algo que não é fruto de qualquer observação sobre o real, mas algo 
criado e apresentado na teoria pura como condição de sua própria existência, por meio da qual se estabelece uma relação normativa entre uma conduta humana e um ato de coerção que, nas palavras de Luis Alberto Warat "não se baseia em qualquer observação efetiva da conduta humana, mas sobre o conhecimento de uma norma jurídica, que estabelece tal relação, enquanto conteúdo da mesma" (WARAT, 1996, p. 61). A imputação serve de auxilio à construção de um modelo normativo que é imaginário, e no qual outra categoria apresentada por Kelsen, "o dever de obediência à ordem estabelecida", é apresentada como ideia lógica e não como um conceito referido a valores (WARAT, 1996, p. 61), realizando o que Warat entende ser um artifício metodológico, o qual se apresenta como "um procedimento idealista, mediante o qual se pressupõe como 'dever' - toda a conduta coercitiva que se tenha estabelecido significativamente em uma norma jurídica" (WARAT, 1996, p. 60).

Para que tivesse organização e não apresentasse contradições na tarefa a que se propôs - de tornar os juristas conscientes a partir da sua libertação da ideologia - Kelsen, utilizando-se da categoria que dita um dever de obediência à ordem estabelecida, imaginou e apresenta ainda o segundo argumento que é traduzido na "norma hipotética fundamental" (KELSEN, 1996, p. 225), cuja existência é pressuposta e que somente tem sentido de existir para organizar sua teoria. Conforme Kelsen, esta norma hipotética, por ele idealizada, realiza um comando por meio do qual "devemos conduzir-nos como a Constituição prescreve, quer dizer, de harmonia com o sentido subjetivo do ato de vontade constituinte, de harmonia com as prescrições do autor da Constituição" (KELSEN, 1996, p. 225).

Ainda, sob uma perspectiva empírica, não é possível encontrar em Kelsen qualquer referencial teórico para formulação de sua ciência do direito, ou mesmo de que forma poderia ser testado seu método científico baseado na imputação - condicionante da coerção punitiva - como meio eficaz de regulação da conduta humana. Conforme Popper, as ciências sociais para que realmente possam ser concebidas como ciências devem apresentar métodos que possibilitem a solução de problemas, que possam ser criticados permanentemente por meio de tentativas de refutação (POPPER, 2004, p. 16). Contrariamente a este entendimento Kelsen - sem também antes identificar um problema a ser resolvido - não submete sua teoria ao falseamento, pelo contrário, afirma logo de início sua certeza de verdade, ao mesmo tempo em que dota de caráter absoluto a suas categorias 
hipotéticas pretensamente destituídas de valor, como condição do próprio método teórico.

É desta forma que Kelsen realiza sua proposta de construção de uma ciência do direito. Vinculando o objeto ao método, sua tarefa cinge-se à construção de um modelo dogmático teórico normativo, em que o objeto se define por meio da apreensão da normatividade posta pelo legislador estatal. Realiza o trabalho de conhecimento deste objeto por meio da dissecação do sistema legislativo e no pressuposto de obediência ao mesmo, sem que se preocupe em entender também sob qual valor está submetido este sistema.

\subsection{Direito e ideologia}

Um intérprete menos atento, poderia ser levado a pensar na possibilidade de fracionamento do direito em "direito que não é ciência" e em algo que poderíamos denominar de "direito que é ciência normativa", resolvendo desta forma as contradições do modelo kelseniano, bem como também problemas derivados de suas inflexões. Ou seja, poderíamos colocar de um lado o conjunto de normas postas com seu conteúdo de valor, que insere-se o processo de realização dialética do direito no processo históricosocial, e do outro lado uma análise meramente descritiva do sistema normativo e pretensamente científica, desvinculando-os. Isto poderia parecer estar em acordo com a proposição anti-ideológica de Kelsen em virtude de que, pelo menos descritivamente, estaria mantido um discurso avalorativo.

Nesta perspectiva, o positivismo jurídico, reduzido à concepção de uma técnica ou ciência do sistema normativo, que por esta característica não abrange a totalidade daquilo que deve ser compreendido como direito, poderia então ainda cumprir um papel restrito ontologicamente a uma autonomia formal, que neste campo cumpriria sua pretensão de desideologização do direito a fim de desvendá-lo, pois estaria colocando a descoberto a realidade normativa. Alguma verdade sobre o direito estaria então demonstrada, seria a apresentação da realidade, ou seja, o direito sem ideologia. Mas, mesmo esta redução seria um engano.

Conforme já registrado anteriormente Kelsen apresenta uma concepção sobre o que é ideologia assinalando esta como algo que encobre a realidade, e portanto a identifica como alienação de consciência, demonstrando um reduzido entendimento quanto aos lugares onde atua o fator ideológico e consequentemente a falta de compreensão de que a opção 
pela utilização de um método dogmático com o intuito de "desvendar" um objeto também está fatalmente comprometida ideologicamente quando encobre valorações. E fatalmente esta visão de Kelsen, teve consequências práticas na sua definição do que seria uma ciência normativa destituída de qualquer valor.

A fórmula de neutralidade proposta pela denominada ciência do direito lastreia-se em uma construção dogmática que tem uma utilidade técnica meramente descritiva do sistema normativo positivo que exclui de sua proposta de investigação das normas jurídicas qualquer postura crítica em relação a este sistema. Kelsen constrói sua teoria sob o entendimento de que o fundamento de validade é buscado em uma norma que lhe é imediatamente superior em um sistema que hierarquicamente tem no topo uma norma pressuposta por força da qual nos devemos conduzir em harmonia com os comandos da autoridade que a estabelece, e que somente pode fornecer o fundamento de validade e não o conteúdo de validade das normas sobre ela fundadas, formando um sistema dinâmico de normas (KELSEN, 1996, p. 219), ao contrário de um sistema que por sua vez teria no topo uma norma fundamental que fornecesse o fundamento de validade e também o conteúdo de validade formaria um sistema estático de normas (KELSEN, 1996, p.218).

Neste denominado sistema dinâmico de normas vislumbrado por Kelsen toda e qualquer norma construída no processo histórico-social da humanidade fica excluída da verificação realizada durante a utilização da técnica descritiva do sistema normativo, por meio de um critério de significação que se denomina 'norma fundamental' da qual deriva exclusivamente um dever de obediência às normas postas. Conforme já exposto, este procedimento, a partir do qual toda a conduta coercitiva estabelecida em uma norma jurídica se pressupõe como um 'dever' apresenta-se como um artifício metodológico por meio do qual se validam e legitimam as normas postas, independente do seu conteúdo. Portanto o dever cumpre um papel ideológico realizando a tarefa de sustentar a formação social existente, sem que nenhuma crítica se possa fazer a ela no âmbito jurídico. Apresenta-se então o motivo pelo qual, para Kelsen, como afirmado por ele mesmo, "todo e qualquer conteúdo pode ser direito" (KELSEN, 1996, p.221).

O positivismo kelseniano apresenta na sua premissa básica, exposta anteriormente, uma visão idealista sobre a ciência. Tem a compreensão de 
que a ideologia encobre a realidade, e que a ciência, como libertadora da verdade, poderia ser realizada a partir da construção de um método dogmático estabelecido a partir de uma premissa hipotética desvinculada de qualquer valor. Entretanto, conforme já dito, este é somente um reduzido entendimento quanto aos lugares onde pode atuar a ideologia.

Kelsen não se atenta ao fato de que a linguagem também exerce papel decisivo como fator ideológico. Ao admitir a ideologia como um conceito axiológico, sob o entendimento de que a linguagem ideológica é também valorativa Ferraz (1998, p.183) explica que os valores são expressões abertas que "em geral constituem critério de avaliação de ações" e que a "valoração ideológica", por sua vez, "tem, por objeto imediato, os próprios valores" sendo "uma metacomunicação que estima as estimativas, valora as próprias valorações, seleciona as seleções, ao dizer ao interessado como este deve vê-las". Portanto, as ideologias, por meio da linguagem, retiram a abertura dos valores, vertendo-se em agentes neutralizadores desses mesmos valores, constituindo-se em valorações encobertas. Quanto a esta neutralização ou encobrimento de valorações é exposto por Ferraz (1998, p.185) que:

Podemos encobrir valorações quando, por exemplo: a) substituímos fórmulas valorativas por fórmulas neutras, como ocorre com a noção de norma fundamental em Kelsen, termo que encobre valorações fundamentais, dando ao sistema jurídico a imagem de um sistema formalmente objetivo; b) quando escondemos a presença inevitável do emissor de uma valoração, dando a impressão de que se trata de uma proposição sem sujeito, caso de expressões do tipo: idéia de Direito, fontes de Direito.

A ideologia, portanto, não se identifica somente com processos de alienação da consciência, a linguagem ao apresentar verdades inquestionáveis que pretendem-se universalmente válidas também atua ideologicamente. E na teoria kelseniana categorias como "dever" e "norma hipotética fundamental", atuam como axiomas criados metodologicamente que, ao mesmo tempo que servem para dar coerência à proposta metodológica apresentada por Kelsen, servindo como ponto inicial de dedução, também atuam ideologicamente neutralizando ou encobrindo valorações. Neste caso, entender qual é a ideologia presente na "Teoria pura do Direito" é perguntar e responder qual o conteúdo valorativo do "dever" de obediência à qualquer norma estatal. 
Ao realizar sua tarefa neutralizadora, o sistema de normas axiomatizadas, objeto da Teoria Pura do Direito, cujo método de investigação pressupõe a destituição de qualquer conteúdo valorativo, apresenta-se como "um sistema ideológico que, em sua materialidade, serve de suporte às atuais formas de organização da vida social" (WARAT, 1996, p.49).

Qualquer método que pretenda ser científico, em qualquer instância do conhecimento - aqui, o direito - e que apresente-se como neutro ou seja, destituído de valor, encontra-se comprometido ideologicamente, sendo este o caso onde enquadra-se o método kelseniano. Conforme expõe Warat (1996, p.51):

[...] a Espistemologia Crítica da Ciência nos ensina que a reinvindicação de neutralidade ideológica e objetividade científica, utilizando um método que rejeita a infiltração da ideologia, não se apóia em sólidos argumentos epistemológicos, mas em justificações valorativas que ao se apresentarem de forma encoberta, tornam-se plenamente eficazes. Assim, optar por uma ciência liberada de ideologia é optar por certa relação entre aquela e o mundo social. Trata-se de uma opção de valor, não pela ciência enquanto tal, mas pela função que a ciência possa cumprir com respeito às práticas sociais. É, portanto, uma opção ideológica feita no interior da epistemologia. No caso da Teoria Pura do Direito, a tentativa de escudar a Ciência Jurídica com uma suposta neutralidade ideológica e política encobre o empenho, talvez inconsciente, de ideologizar esse saber, preservando, assim, seu poder.

Assim, contrapondo-se à proposta avalorativa e apolítica de Kelsen é importante afirmar que a compreensão sobre o direito, não pode ser reduzida ao conhecimento do sistema legislativo estatal ou do o conjunto de normas postas, mas também daquilo que se contrapõe a este sistema e a estas normas, e que pode ser nomeado como normas contrapostas, agindo como aquilo que Roberto Lyra Filho designa de uma multiplicidade de conjuntos de normas jurídicas que constituem o processo de realização dialética do direito (LYRA FILHO, 1999, p.74). Nesta concepção a norma somente se positiva tendo por contraposição uma outra realidade normativa, sem a qual ela não teria motivo para ser positivada. É contra esta outra realidade normativa que existe um choque permanente. Estas duas realidades normativas, a norma posta e a norma contraposta - é bom salientar - não derivam de um exercício metafísico de característica jusnaturalista, mas 
sim do processo histórico-social em que se apresentam as contradições materiais na vida humana. E por isto não são imutáveis ou cristalizadas e nem mesmo perenes.

A partir do momento em que se faz a opção pela positivação de uma norma em detrimento de outra, isto não decorre simplesmente da tradução de uma vontade, mas também da contraposição a outra ou mais vontades. No momento em que uma das vontades se faz prevalecer, seja por meio legitimo ou ilegítimo, positivando a norma de sua preferência, "realiza-se" materialmente uma opção política. Nesta opção política que se impõe, a qual é derivada de um inicial confronto entre opções políticas distintas, está a germinação do direito. Dizer que o direito somente nasce com o Estado, ou a partir deste, significa negar a própria razão de ser do Estado, cuja existência somente tem sentido a partir da necessidade de imposição de uma norma ou de um sistema normativo. Esta dimensão política é portanto a primeira e principal característica daquilo que denominamos direito e será impossível a compreensão desta dimensão caso o direito fique reduzido ao sistema normativo positivado ou a um método científico que procura desvendá-1o.

\section{CONCLUSÃO}

Analisar e compreender o positivismo jurídico de tipo kelseniano significa entender o papel que desempenha até hoje, mantendo-se como uma das principais teorias jurídicas da modernidade, e também entender onde está sua fragilidade.

Não se poder negar a importância que pode ter um método - como faz o positivismo jurídico - que dogmaticamente descreva um sistema legislativo estatal, principalmente quanto à estrutura deste sistema e quanto aos critérios para positivação ou expulsão da norma frente ao sistema. Mas o mesmo não se pode dizer de sua pretensão retórica de apresentar-se como neutro e livre ideologia, uma vez que todas as teses jurídicas apresentam comprometimentos ideológicos e disto não está livre o positivismo jurídico normativista. Uma indicação da presença de uma concepção ideológica no método kelseniano - não a única - é o seu próprio esforço de apresentar-se primeiro como neutro e depois como ciência, desprezando o fato de que mesmo os métodos científicos traduzem um agir ideológico.

Ressalta-se ainda, quanto à sua pretensão científica, que o reconhecimento do juspositivismo como sendo uma ciência, que deixa a investigação do conteúdo 
normativo e a observação do resultado de sua aplicação a cargo das demais disciplinas, deixaria esta "ciência" na condição de negar a sua própria autonomia e por este motivo não pode ser entendida como sendo uma ciência, mas somente como uma técnica de explicação normativa.

Definir o direito como um sistema normativo ou um ordenamento jurídico buscando, na ânsia de dar-lhe conformidade científica, é uma atividade reducionista do direito. Além disto, a proposta kelseniana realiza um exercício cientificista - mas não científico - que entendendo a ciência como realizadora da verdade, de forma temerária, procura conjugar aquilo que não se pode imbricar - direito e pretensão de verdade. Realmente a ciência pode ser definida como a aquisição de conhecimento sistematizado com o objetivo de desvendar o seu objeto e tem compromisso com uma certa objetividade cuja possibilidade de apreensão da verdade é, por sua vez, questionável. Contudo isto não se aplica ao direito, no qual a ideia reguladora não é o encontro com a objetividade ou com a verdade, mas sim a realização da justiça ou, pelo menos, de uma resposta adequada, e que poderá ter sua fonte de racionalidade não exclusivamente fixada na atividade legislativa.

O método desenvolvido por Kelsen somente pode apresentar a verdade sobre ele mesmo, ou seja, a descrição de um sistema normativo comprometido com um valor absoluto: o dever de que seja ele mesmo, cumprido. E não apresenta condições de compatibilizar-se com as concepções jurídicas que se apresentam comprometidas com o valores democráticos e com a aproximação entre direito e justiça realizáveis a partir da preservação de conquistas democráticas e sociais.

\section{REFERÊNCIAS}

ALEXY, Robert. Teoria ;dos Direitos Fundamentais. 2. ed. Tradução de Virgílio Afonso da Silva. São Paulo: Malheiros, 2011.

COELHO, Luiz Fernando. Positivismo e neutralidade ideológica em Kelsen. In: PRADO, Luiz Regis; KARAM, Munir; REALE, Miguel. Estudos de Filosofia do Direito. uma visão integral da obra de Hans Kelsen. São Paulo: Revista dos Tribunais,1985. p.46-62.

DIMOULIS, Dimitri. Positivismo Jurídico: Introdução a uma teoria do direito e defesa do pragmatismo jurídico-político. São Paulo: Método, 2006. (Coleção Professor Gilmar Mendes; 2). 
DWORKIN, Ronald. Uma questão de princípio. 2. ed. Tradução de Luís Carlos Borges. São Paulo: Martins Fontes, 2005.

EAGLETON, Terry. Ideologia: uma introdução. Tradução de Silvana Vieira, Luís Carlos Borges. São Paulo: Unesp, Boitempo, 1997.

FERRAJOLI, Luigi: Derecho y Razón: teoría del Garantismo Penal. Madrid: Trotta, 1998.

FERRAZ JR. Tércio Sampaio. A Função social da dogmática jurídica. São Paulo: Max Limonad, 1998.

HABERMAS, Jürgen. Direito e democracia: entre facticidade e validade. 2. ed. Tradução de Flávio Beno Siebeneichler. Rio de janeiro: Tempo Brasileiro, 2012.

KELSEN, Hans. Teoria pura do direito. 5. ed. Tradução de João Baptista Machado. São Paulo: Martins Fontes, 1996.

KUHN, Thomas S. A estrutura das revoluções científicas. Tradução de Beatriz Vianna Boeira e Nelson Boeira. São Paulo: Perspectiva, 2005. (Debates; 115).

LÖWY, Michael. Ideologias e ciência social: elementos para uma análise marxista. 19. ed. São Paulo: Cortez, 2010.

LYRA FILHO, Roberto. O que é direito. São Paulo: Brasiliense, 1999.

MARQUES NETO, Agostinho Ramalho. A ciência do Direito: conceito, objeto, método. 2. ed. Rio de Janeiro: Renovar, 2001.

MIAILLE, Michel. Introdução crítica ao Direito. Lisboa: Estampa, 2005.

MORIN, Edgar. Ciência com consciência. Rio de Janeiro: Bertrand Brasil, 2000. 
POPPER, Karl Raymund. Lógica das ciências sociais. 3. ed. Rio de Janeiro: Tempo Brasileiro, 2004.

WARAT, Luis Alberto. A Pureza do Poder. Florianópolis: Editora da UFSC, 1996.

Artigo recebido em 14/10/13 e aprovado para publicação em 21/11/13

Como citar: CADEMARTORI, Luiz Henrique Urquhart; ESTEVES, João Luiz Martins. A ideologia da neutralidade: uma abordagem sobre o juspositivismo normativista e seus limites frente à democracia social. Scientia Iuris, Londrina, v.17, n.2, p.193-210, dez.2013. DOI: 10.5433/2178-8189.2013v17n2p193. 